\title{
Terapias Alternativas: Uma Questão Contemporânea em Psicologia
}

Controvérsias sobre a prática de psicoterapias alternativas por psicólogos vêm provocando inúmeros debates. Estas práticas são criativamente estudadas por meio de entrevistas com terapeutas e clientes a respeito de suas experiências. As questōes sobre a eficiência e eficácia das terapêuticas convencionais e alternativas são discutidas, considerando-se os aspectos metodológicos e as implicaçōes epistemológicas dos

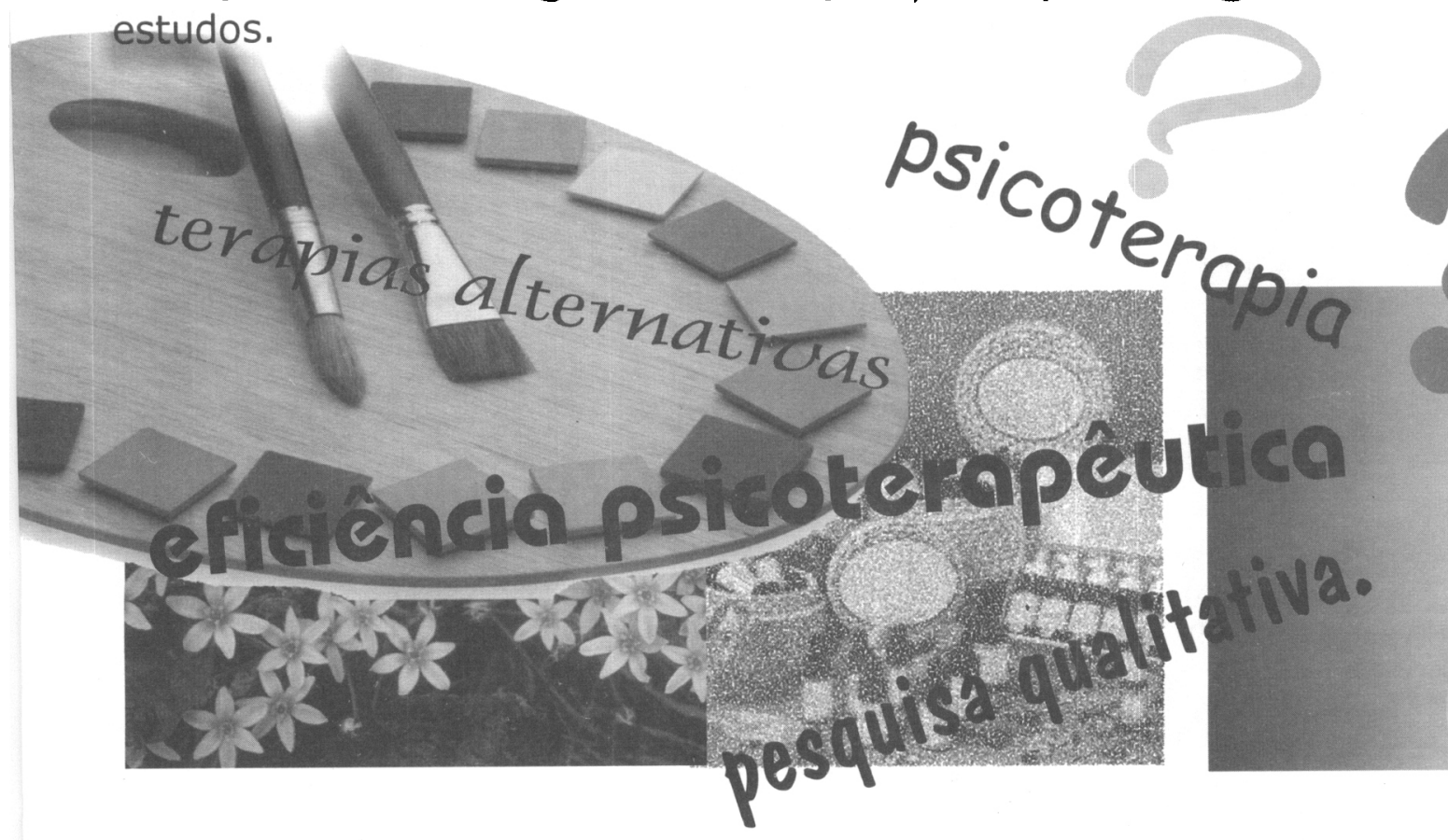

O número de pessoas que praticam terapias ditas alternativas e de "centros de terapias alternativas" é consideravelmente grande, e tende a aumentar, bem como suas clientelas. Como exemplo destas técnicas pode-se mencionar: "Cromoterapia", "Florais de Bach", "Terapia de Regressão a Vidas Passadas" (TRVP), e "Psicologia Transpessoal". Em Cursos de Psicologia encontram-se muitos estudantes que são admiradores destas terapias, alguns que já são praticantes e outros que pretendem dedicar-se a essas atividades. Um indicativo desta tendência é o grande número de cartazes anunciando cursos, encontros e serviços nos corredores de nossas universidades, próximo aos cursos de psicologia.

Sobre as terapias alternativas, seus praticantes, seus clientes e sua proliferação, não há dados estatísticos disponíveis e tampouco há conhecimento sobre a sua eficiência. Entende-se por eficiência a indicação ou especificação da natureza do benefício obtido por pessoas que se submentem a esses tratamentos (Gomes, Reck, \& Ganzo, 1988). Marques (1994) interpretou o movimento das práticas alternativas como tratando-se de efeito da pós-modernidade e das mudanças mundiais na Psicologia. Em seu estudo, emergiram como categorias a mudança de paradigma e a psicologia transpessoal, que reúne alguns dos estudos e investigações relacionados às práticas alternativas.

Sabe-se que o campo da Psicologia caracteriza-se pela ausência de um vocabulário comum e de um consenso sobre seus princípios básicos, além de haver um grande número de

Gustavo Gauer, Mariane L. de Souza, Fábio Dal Molin e William B. Gomes

Instifuto de Psicologia UFRGS 
escolas com propósitos distintos (Omer \& Strenger, 1992). Se tal dificuldade em se traçar padrōes dentro do campo da Psicologia estende-se à psicoterapia convencional, mais complicado ainda será fazê-lo com as terapias alternativas. Entende-se que as teorias na área da Psicologia tidas por científicas são aquelas que incorporam, com uma ou outra variaçāo, preceitos de uma lógica empírica-racional na construção de seus aparatos teóricos e subsistem submetendo esses aparatos a avaliaçōes que permitam demarcar seu escopo (Tourinho \& Carvalho, 1995). Incluemse nesse grupo as teorias do campo da Psicologia que, sem.corresponder necessariamente a um modelo de ciência natural, deram origem a práticas de investigação, produção e validaçāo de conhecimento que podem ser consideradas científicas. As práticas alternativas são contempladas, neste sentido, como aiternativas à Psicologia na medida em que pretendem dar conta de problemas tradicionalmente reservados à disciplina psicológica, valendo-se, contudo, de recursos explicativos que não se confundem com aqueles empregados por teorias científicas. Os recursos explicativos das práticas alternativas, ao contrário das teorias científicas, contêm elementos místicos, religiosos ou supersticiosos. O alternativo não se define, então, pela atividade prescrita em si, nem pelo fato de se constituir como uma experiência nova no campo da intervenção psicológica, mas pelo tipo de conhecimento veiculado e pelas concepçōes de homem e de mundo a eles subjacentes. (p. 85)

Constata-se uma forte influência do pensamento oriental sobre as terapias alternativas. Os tratamentos caracterizam-se pelo uso de meditaçāo e de relaxamento, e por apresentarem pressupostos holísticos, entendidos como unidade entre corpo e alma, sendo que o termo alma inclui tanto os aspectos mentais como espirituais. A compatibilidade entre meditação e psicoterapia já foi estudada, concluindo-se que psicanalistas consideram a prática da meditação como contraproducente para o processo terapêutico, enquanto psicoterapeutas transpessoais acreditam no contrário (Bogart, 1991). A psicologia transpessoal faz uso de técnicas convencionais em conjunto com práticas conscientizadoras orientais, a fim de lidar com o chamado "nível transpessoal" (Tabone, 1992). Elementos comuns entre psicanálise, psicologias humanista e transpessoal, e zenbudismo foram investigados (Rhee, 1990). O autor constatou que as propostas dessas abordagens seriam as mesmas, sob diferentes nomenclaturas. Na comparaçāo entre o processo psicanalítico e a prática zen-budista encontrou-se convergências no entendimento das relaçōes entre dependência e hostilidade, e nas ênfases em relacionamento interpessoal, fortalecimento do ego e interpretaçāo. Estudos sugerem que as várias terapias ocidentais tornam-se mais eficientes quando combinadas com sistemas orientais de autocontrole (Ikemi, 1990) e que há aspectos positivos no uso de certas ervas pela medicina oriental no tratamento da depressāo (Sarai, 1992).

Numerosos estudos sobre psicoterapia têm abordado o tema da importância do contexto cultural no processo psicoterapêutico, especialmente sobre a sua eficiência. Comparaçōes transculturais relativizam a validade dos métodos atuais de psicoterapia (Littlewood, 1990; Pfeiffer, 1991). As representaçōes de pacientes e terapeutas sobre conceitos de saúde e doença influenciam em $60 \%$ a eficácia terapêutica; no entanto, o papel da cultura dificilmente é considerado pela maioria das teorias (Havenaar, 1990). Bergin e Jensen (1990) investigaram as mudanças nos valores religiosos de psicoterapeutas americanos. Constataram que esses profissionais não indicaram afiliações a organizações religiosas convencionais mas sim envolvimento em práticas espirituais nāo convencionais. Os autores identificaram essa tendência como um "humanismo espiritual" e acreditam que esta nova postura poderia aproximar a terapia de um público mais religioso. Estudando-se a relaçāo entre a cura carismática católica $\mathrm{e}$ psicoterapias, observou-se que os terapeutas que tentam integrar as duas visōes vêm encontrando dificuldades práticas relacionadas às diferenças nos pressupostos (Csordas, 1990). Pesquisados os chamados "tratamentos nativos" da cultura africana, praticados por curandeiros e bruxos, através de exorcismo e sacrifícios, constatou-se a importância de se levar em consideração os aspectos culturais quando na transposição de uma teoria de uma cultura para outra (Vontress, 1991). Por outro lado, observa-se na literatura relatos de tentativas de compreensão de práticas nativas africanas no sentido de saber o que estes tratamentos podem oferecer às terapias ocidentais (Straker, 1994). Os ritos afrobrasileiros e seus modelos míticos de comportamento foram estudados por Monique Augras (1983). A autora considera que num País como o Brasil, com a enorme riqueza de culturas e subculturas que se opōem, se interpenetram, 
se chocam e se integram, não há muito sentido em aceitar os modelos euro-americanos como fontes exclusivas do saber. (p. 12)

A teoria de Carl Gustav Jung (1964) apresenta notáveis considerações acerca das interaçōes entre cultura, mitologia, religião, psicologia e psicoterapia, introduzindo conceitos de uso relativamente corrente, como inconsciente coletivo e arquétipo. Na verdade, Jung é um dos autores mais citados pelos terapeutas alternativos. Fadiman e Frager (1979), em seu conhecido livro sobre teorias da personalidade reconhecem o interesse nos sistemas filosóficos orientais ocorrido nos Estados Unidos: Numa época de contínuo questionamento a respeito dos pontos de vista estabelecidos sobre religiāo, ciência e sistemas políticos organizados, há uma busca correspondente por modelos de comportamento humano alternativos, modelos que sejam baseados em uma observaçāo diferente e que conduzam a conclusōes alternativas. (p. 281). Tal colocaçāo parece pertinente à situaçāo de escalada que os sistemas alternativos experimentam atualmente no Brasil.

A proposta deste estudo é estabelecer uma primeira aproximação com as práticas psicotepêuticas alternativas. Neste trabalho, define-se como terapias alternativas aquelas técnicas cujos pressupostos teóricos e filosóficos e os critérios de formação não estejam relacionados diretamente com a tradiçāo das psicoterapias adotadas por psicólogos e psiquiatras, conforme indicado por Dorin (1978). Interessa saber quais os motivos que levam um leigo ou um psicólogo a tornar-se um psicoterapeuta alternativo, qual a formação necessária para o exercício dessa prática, que tipo de resultados tem-se alcançado e como os terapeutas descrevem suas experiências com essas terapias. Sobre os pacientes, pretende-se descobrir por que eles procuram uma terapia alternativa, como eles descrevem suas experiências e quais benefícios encontram nesse tipo de terapia.

\section{Ḿ́tTODo}

Participantes

Participaram deste estudo dez terapeutas e dez pacientes de psicoterapias alternativas. Os primeiros terapeutas foram localizados a partir de indicaçōes de estudantes de psicologia que acompanham os movimentos de psicoterapia alternativa. Os demais terapeutas foram localizados por indicaçào dos primeiros entrevistados. Estes terapeutas representavam quatro modalidades de terapias alternativas (Tabela 1 ).

Tabela 1 - Informantes da Pesquisa: Terapeutas

\begin{tabular}{l|lll|l|l|}
\hline Sujeito & Idade & Sexo & Formação & Prática Terapêutica & Tempo de atuação (anos) \\
\hline $\mathbf{1}$ & 31 & F & Est. Psicologia & Bioterapia & 2 \\
$\mathbf{2}$ & 29 & F & Est. Psicologia & Abordagem Psicossomática & 6 \\
$\mathbf{3}$ & 34 & F & Psicóloga & TRVP & 3 \\
$\mathbf{4}$ & 45 & F & Adm. Empresas & Massoterapia & 4,5 \\
$\mathbf{5}$ & 35 & M & Psicólogo & Abordagem holística & 10 \\
$\mathbf{6}$ & 47 & F & Arquiteta & Grupo de auto-ajuda espírita & 6 \\
$\mathbf{7}$ & 62 & M & Psicólogo & TRVP & 5 \\
$\mathbf{8}$ & 32 & F & Psicóloga & TRVP & 2,5 \\
$\mathbf{9}$ & 28 & F & Psicóloga & Abordagem holística & 4,5 \\
$\mathbf{1 0}$ & 46 & F & Psicóloga & Floral & 1
\end{tabular}

Os pacientes que participaram da pesquisa foram indicados pelos próprios terapeutas. Esses pacientes representavam as várias modalidades de tratamentos, conforme a Tabela 2.

Tabela 2- Informantes da Pesquisa: Pacientes

\begin{tabular}{|c|c|c|c|c|c|c|}
\hline Sujeito & Idade & Sexo & Ocupação & Terapia & Duraçâo (meses) & Frequiencia \\
\hline 1 & 43 & $\mathrm{~F}$ & Est Psicologia & Abordagem psicossomática & 40 & $1 / 15 d$ \\
\hline 2 & 34 & $\mathrm{~F}$ & Professora & Abordagem psicossomática & 18 & Variável \\
\hline 3 & 49 & $\mathrm{~F}$ & Aux. Enfermagem & Floral & 24 & $1 / \mathrm{S}$ \\
\hline 4 & 58 & $\mathrm{~F}$ & Professora & Grupo auto-ajuda espírita & 24 & $1 / S$ \\
\hline 5 & 47 & $\mathrm{~F}$ & Professora & Grupo auto-ajuda espírita & 36 & $1 / S$ \\
\hline 6 & 38 & $\mathrm{~F}$ & Func. Pub. Federal & TRVP & 14 & $1 / S$ \\
\hline 7 & 42 & $M$ & Enfermeiro & TRVP & 18 & $1 / \mathrm{S}$ \\
\hline 8 & 35 & $M$ & Pequeno Empresário & TRVP & 18 & $1 / 5$ \\
\hline 9 & 32 & $M$ & Comerciário & Bioterapia & 11 & $1 / \mathrm{S}$ \\
\hline 10 & 52 & $\mathrm{~F}$ & Assist SocialAbord. & Holística & 20 & $1 / \mathrm{S}$ \\
\hline
\end{tabular}




\section{Instrumento/Procedimento}

O instrumento utilizado na obtenção de dados pela presente pesquisa constituiu-se de dois protocolos tópicos de seqüência flexível (Patton, 1990), para entrevistas individuais, dirigidos a cada um dos grupos. O protocolo utilizado como roteiro para a entrevista dos pacientes é o mesmo utilizado em estudos anteriores sobre a percepção de pacientes sobre sua psicoterapia (Gomes, Reck \& Ganzo, 1988; e Gomes, Reck, Bianchi \& Ganzo 1993). Os protocolos (Anexo 1) têm conteúdo baseado em sondagem de campo e serviram à realização de entrevistas semi-estruturadas, visando a livre expressão das experiências conscientes dos sujeitos a partir de perguntas formuladas de modo a facilitar suas descriçōes. As entrevistas foram realizadas e gravadas em audioteipe nas residências ou locais de trabalho dos participantes. Todos os participantes foram informados dos propósitos da pesquisa e aceitaram dar a sua contribuição de forma voluntária (consentimento informado). A seguir, o material foi transcrito na íntegra, totalizando cerca de 12 horas de entrevistas e 300 páginas de transcrições. As entrevistas foram formatadas para o uso do software de análise qualitativa Ethnograph 3.0, que possibilita a delimitação e listagem das categorias de análise.

\section{Critério de Análise/Síntese}

Os depoimentos recolhidos nas entrevistas foram analisados através de critérios qualitativos (Gomes, 1997; Lanigan, 1988; Patton, 1990). O critério de análise $\mathrm{e}$ síntese foi organizado em três etapas sinérgilcas. Essas etapas são conhecidas como descrição qualitativa, redução ou especificação da descrição e interpretação. Note-se que é um critério de análise porque consiste, primeiramente, numa separação de partes de um tódo, e numa demarcacão de unidades de sentido do texto original (descrição). Mas é também uma síntese porque agrupa as partes separadas (redução) em novas partes (tipologias. categorias) que são acrescentadas ao todo (interpretaçāo). Na passagem da descrição para a redução vivencia-se uma experiência que é a presença de um novo objeto para a consciência, que é definida como interpretação. Tratase, na verdade, de uma interpretaçăo hermenêutica, isto é, circunscrita ao contexto da experiência em foco e que tem a função metodológica de especificar o valor da relação entre a descrição e a redução. É bom lembrar que esta metodologia focaliza seu objeto de estudo de uma maneira globalizante incluindo: o acta (o que é feito), o data (o que é dado) e o capta (o que é tomado). No caso deste estudo têm-se os depoimentos dos terapeutas e dos pacientes (acta), obtido através de entrevistas (data) como entendido pelos pesquisadores (capta). No entanto, a percepção dos pesquisadores não pode ser interpretada como a expressāo de uma subjetividade. A comunalidade encontrada nos depoimentos valida-se na intersubjetividade de um mundo compartilhado, que é a especificação de um contexto de relaçōes interpessoais. Temos, portanto, o produto objetivo de um ato comunicativo, entre entrevistador e entrevistado, que esclarece e explica o material estudado.

\section{DESCRIC̣ĀO}

A descrição das respostas dos entrevistados divide-se em duas partes. Primeiro apresenta-se as categorias (especificaçōes tipificadoras) emergentes da leitura dos relatos dos terapeutas e dos pacientes, respectivamente. As frases em itálicos indicam transcrições literais das entrevistas. Em geral, são frases que sintetizam ou definem as posiçōes dos entrevistados.

\section{Teraplas Alternativas: A percepção dos terapeutas}

\section{1-Da Procura pelo Tratamento}

De acordo com os depoimentos dos terapeutas, suas clientelas formam-se por indicação de outros pacientes ou de outros profissionais; através de divulgação em palestras, programas de rádio e televisão ou encaminhamento por orientadores de entidades religiosas que oferecem tratamentos.

\section{2-Dos Sintomas dos Pacientes}

A maior demanda, na percepção dos terapeutas, está na esfera das relaçōes interpessoais. São dificuldades no casamento, na família ou no trabalho. São mencionados ainda problemas de depressão, fobias, ansiedade, dificuldades de aprendizagem, insegurança, frigidez e pânico. Há, contudo, pessoas que buscam atendimento por causa de problemas fisicos. Nestes casos, as maiores incidências são dores musculares, problemas de coluna, problemas digestivos e obesidade. Foram também mencionados problemas ginecológicos, articulares e circulatórios. 


\section{3-Dos Pacientes}

$\mathrm{Na}$ percepção dos terapeutas, as pessoas que procuram os tratamentos alternativos estão todas em um processo de busca pessoal. Há aqueles que estão apenas procurando soluçāo para um problema físico, como por exemplo uma dor localizada, e que nem sempre integram o sintoma ao processo psicológico pelo qual estão passando. Outros estão buscando alguma coisa que não sabem o que é ou trazem problemas que não sabem definir exatamente. Há situações de crise existencial e há aqueles que simplesmente buscam um terapeuta mais compreensivo. Em conseqüência, a terapia às vezes funciona para o paciente como catalisadora de um processo de autoconhecimento. Sua permanência em terapia é breve. Em outros casos, o terapeuta aponta que o tratamento serve como a base que o paciente procurava para levar adiante $o$ seu processo de busca interior. "Elas não buscam mais aquele psicólogo tradicional, né (...) mas que eles possam falar da religião deles, que eles possam ouvir, de vez em quando, uma coisa diferente $\mathrm{e}$ isso não estar dentro da loucura" (T8).

\section{4 - DaPrática Terapêutica}

As definiçōes de terapia oferecidas pelos terapeutas variaram de acordo com sua versāo de identificação da abordagem. Houve definiçōes mais abertas, como por exemplo, "é uma abordagem psicossomática" (T2) e definiçōes mais específicas, como, por exemplo, "a terapia regressiva a vivências passadas consiste no seguinte: a pessoa relaxa e, através do relaxamento, a pessoa revive um acontecimento traumático do seu passado"(T7). Em contraste, houve definiçōes fragmentadas baseadas nas técnicas utilizadas, em descriçōes de certas qualidades do trabalho ou em comparações com a psicoterapia tradicional. Por fim, apareceram também definiçōes contraditórias no que se refere à identidade com a terapia:

"Então, eu tô fazendo uma terapia, uma medicina que é alternativa, não é uma terapia, é um a companhamento terapêutico no tratamento de florais de Bach" (T10).

Os recursos técnicos utilizados pelos terapeutas em suas práticas estão aqui agrupados conforme a sua linha ou aborda- gem. Na TRVP, são utilizados o relaxamento, a visualização criativa e a hipnose ericksoniana, que é definida como uma "hipnose consciente", na qual o paciente se lembra de tudo o que aconteceu. Considera-se que as técnicas agem conjuntamente no processo. A visualizaçāo criativa é utilizada como uma preparação para o paciente entrar no processo hipnótico, e ambos só ocorrem em um estado de total relaxamento. Nesta técnica, o terapeuta pede para o paciente fechar os olhos e imaginar lugares ou situaçōes que lhe sejam agradáveis. Os terapeutas de regressão concordam sobre a necessidade de uma anamnese para determinar se o paciente necessita ou nāo da técnica reơressiva.

Os terapeutas que centram a sua prática nos Florais de Bach ressaltam a importância da conversa com o paciente e de que ele acredite que aquela essência que ele tomou irá Ihe fazer bem.

Os terapeutas de abordagem psicossomática utilizam a massagem em conjunto com os florais e óleos aromáticos essenciais (aromaterapia) os quais, segundo os depoentes, possuem efeitos sobre a psique. As técnicas fazem parte de uma estrutura relativamente bem definida. Inicia-se com uma anamnese para se definir quais problemas devem ser tratados. Enfatiza-se que são sempre considerados os níveis psíquico, energético e corporal. Para tanto, utiliza-se massagem e exercícios físicos.

Nas terapias de abordagem holística, os terapeutas possuem um repertório de técnicas e as utilizam conforme o caso, como informa T9: "Olha, eu aprendi muito com a antropossofia... a usar aquarela com pessoas muito rígidas. Trabalha com a estrutura das cores. Eu gosto de usar argila, uso a regressão, uso o floral, uso a pintura, guache, também... e a verbalização". Como recurso técnico desta abordagem é citada, ainda, a cromoterapia (terapia das cores), que pode ser associada à musicoterapia, onde um determinado estímulo luminoso é alíado a uma freqüência sonora, $o$ que produziria efeitos curativos. Além da intervenção verbal, utiliza-se a "visualização criativa", "eletromagnetoterapia", recursos orientais (como histórias do I Ching) e vendas nos olhos do paciente.

Coordenadora de grupos de autoajuda espirita, T6 diferencia-se dos demais terapeutas, pois não utiliza nenhuma técnica especifica, valendo-se da sua intulção e da experiência em coordenar grupos.

\author{
"Elas não buscam \\ mais aquele \\ psicólogo \\ tradicional, né (...) \\ mas que eles \\ possam falar da \\ religiỡo deles, que \\ eles possam ouvir, \\ de vez em quando, \\ uma coisa diferente \\ e isso não estar \\ dentro da loucura" \\ (T8).
}




\section{5 - Das Crenças e Sentimentos sobre a Terapia Alternativa}

Os terapeutas descrevem seu trabalho e seu envolvimento com os tratamentos alternativos como uma experiência de elaboração dos próprios conflitos. Essa elaboraçāo é vista como uma necessidade ou mesmo como uma convicção, como relata o sujeito T2: "Me dá vontade, assim, de falar agora, do quanto a gente como terapeuta tem que ser um paciente (...) Você não vai conseguir tratar a pessoa, naquilo que pra ti ainda tá mal resolvido". Eles declaram aģir na relação com o paciente como um agente facilitador. No entanto, alguns sujeitos caracterizam a situação de terapeuta também como de liderança e até mesmo de poder. "Então, eu vejo assim, que muitas pessoas me dão um tremendo poder, eu sou quase $0 .$. sei lá, o mago que ajuda elas, um religioso, o grande doutor, né" (T5). Outra constante nos relatos dos terapeutas é a descrição de uma postura de questionamento do próprio trabalho, dúvidas sobre sua eficácia ou sobre a própria atuação, e o cuidado com a reputaçāo profissional.

\section{6-Do Processo Terapêutico}

As descriçōes do processo terapêutico variam de acordo com as respectivas abordagens. Na TRVP o processo terapêutico consiste em uma regressāo de memória a uma situaçāo passada onde ocorreu um trauma, e uma conseqüente elaboraçāo desta vivência do paciente. Tal processo se daria pelo fato de a pessoa estar ligada à situação traumática de forma pouco saudável, por tê-la vivenciado sem refletir. Nesse processo, o terapeuta ajudaria o paciente a adquirir a consciência do trauma e a interpretar todos os simbolismos que aparecem durante a regressão. A partir daí, seria possível fazer uma "reprogramaçāo" e "dàr uma nova ordem para o inconsciente" (T8). Segundo os terapeutas de regressão, o processo de cura completo se dá, em média, em dez sessōes.

Nos tratamentos psicossomáticos, o processo terapêutico ocorre quando a pessoa trata seu problema físico e, conjuntamente, descobre que as causas destes problemas podem ser psíquicas. Um exemplo é o relato de T2: "As técnicas, elas agem a cada nível, sinergeticamente. Só no físico não adianta tu tratares, que voltam os sintomas". As técnicas agiriam no sentido de equilibrar "o corpo físico" e o "corpo energético" da pessoa. pessoa, pois cada essência representaria 'a energia positiva em relação ao mal-estar sentido pelo paciente, visto como uma "energia negativa". O processo tem por base uma tomada de consciência dos próprios problemas, do mais superficial ao mais profundo: "Como toda terapia, a terapia floral é como o descascar de uma cebola, vai tratando as partes mais superficiais, vai aparecendo, de uma forma assim, dá pra se dizer, as partes mais profundas, aquelas do núcleo" (T10).

\subsection{Da alta}

A alta é decidida em conjunto com o paciente; tanto um terapeuta pode observar a remissão dos sintomas e as mudanças substanciais no modo de ser do paciente, quanto este explicitar que sente-se bem e curado.

\section{Terapias Alternativas: A percepção dos pacientes}

\section{1 - Da Procura pelo Tratamento e seus motivos}

Os pacientes informaram que a aproximação de uma terapia alternativa deu-se através da indicaçāo, por um familiar ou conhecido, de uma instituição ou terapeuta; ou por acaso, através de anúncios, palestras e meios de comunicação. Os pacientes referemse à percepção de seus problemas como motivo principal da busca pelo tratamento. Eles definiram-se, na época da procura do tratamento, como pessoas desorganizadas, muito rígidas, "fechadas", com baixa autoestima, muito tensas, com muitos medos. Essas pessoas podiam estar, ainda, conforme suas descriçōes, em um periodo de questionamento e "angústia existencial", e decepcionadas com terapias convencionais.

\section{2 - Dos Terapeutas}

Os pacientes descrevem os terapeutas como estimuladores da reflexão e dos questionamentos. Os terapeutas demonstram vontade de curar o mais rápido possivel: "a gente vê que ela conduz de uma forma realmente para resolver os problemas, (...) sem se preocupar com a quantidade de tempo" (P7). São profissionais que apóiam o paciente fora do ambiente terapêutico, como em telefonemas fora do horário de atendimento: "Eu me senti bem apoiada por ela; é uma pessoa super atenciosa, tipo... dá os florais, se dá algum efeito colateral ou se tu te sente 
angustiada, tu telefona pra ela" (P3).

A relação terapêutica foi considerada muito boa pelos pacientes. Quando algum aspecto negativo foi apontado ressalvou-se que não comprometeu o tratamento: "Acho ela uma pessoa autoritária, bem prepotente, mas eu acho que ela conduz muito..." (P5). Houve relatos de mal-estar passageiro na relação com o terapeuta, posteriormente interpretado como uma reação natural à abordagem de alguma questão delicada, necessária ao bom andamento da terapia. Houve menção de amizade com terapeuta, de sentir-se identificado com ele, ou de tomá-lo como modelo.

\section{3-Da Vivência Terapêutica}

Sobre a vivência terapêutica os pacientes destacaram a liberdade que o terapeuta dá para falar, sendo isso entendido como um dos fatores que caracterizam a terapia como alternativa: "eu considero, assim, que seja alternativa, porque eu posso falar do que eu quiser, sabe, ele não conduz a entrevista em nenhum momento" ( $\mathrm{P} 10)$. $\mathrm{O}$ assunto tratado em cada sessão, segundo os entrevistados, é trazido de improviso, sem um planejamento prévio, a não ser quando há algum assunto pendente de uma sessão anterior. Os pacientes geralmente sentem-se bem após as sessōes, com a impressão de que conseguiram resolver alguma coisa, ou de que estāo mais conscientes dos próprios problemas. Os exercícios de relaxamento ou meditação, presentes em todas as abordagens, são considerados eficazes pelos pacientes.

\section{4 - Das Crenças e Sentimentos sobre a Terapia Alternativa}

A terapia é considerada pelos pacientes como um momento de reflexão, para "pensar coisas da gente" ou para dedicar-se a si mesmo. Esses momentos, entāo, propiciam uma tomada de consciência, com a orientação do terapeuta e com o auxílio das técnicas utilizadas. Os pacientes relatam que a terapia é "uma coisa boa", que sentem-se bem, na maioria das vezes, com exceção de algumas sessōes, aquelas em que experimentaram momentos dolorosos decorrentes de muita exposição a temas delicados.

\section{5 - Das Mudanças Decorrentes do Tratamento.}

Os pacientes atribuem ao tratamento melhoras na capacidade de lidar com os próprios problemas, mudanças na visão de mundo e na relação com as outras pessoas e a remissão de sintomas físicos. Tais mudanças, segundo os pacientes, foram percebidas não só por eles mesmos, mas também por familiares e amigos.

\section{6-Da alta}

A alta é descrita pelos pacientes como o resultado de um acordo entre os sentimentos do paciente e a determinação do terapeuta. $O$ paciente pode ter a consciência de ter mudado certos comportamentos, de não mais depender do terapeuta, ou, simplesmente, "estar pronto." Os pacientes relatam, contudo, dificuldades em fazer uma previsão exata sobre um eventual final de tratamento. Eles vinculam esse prognóstico a uma avaliaçāo dos objetivos já alcançados e de sua capacidade de viver sem a terapia ou sem o terapeuta.

\section{Redução Qualitativa e Interpretação}

A análise indutiva (redução) concentrou-se na investigação do sentido que vai sendo construído entre as três fases da pesquisa. Assim, detém-se no exame das seguintes relações: 1) procedimentos para criação de evidência, isto é, a entrevista enquanto recuperação de uma experiência retrospectiva (acta); 2) procedimentos de documentação de evidência, a gravação em audioteipe da entrevista (data, incluindo transcrição e entonação); 3) procedimentos para interpretação da mensagem, tanto na perspectiva compreensiva da fala dos entrevistados (descrição) quanto na perspectiva crítica dos pesquisadores (reduçāo e interpretação). Note-se neste critério de análise a ocorrência de duas etapas distintas de pesquisa. A primeira foi a composição de uma descrição enquanto síntese das entrevistas que é um procedimento interpretativo. Segundo, a análise da descrição apresentada enquanto uma proposta para debate de uma interpretação crítica, apresentada a seguir.

1. A compreensão e interpretação das descriçōes e informaçōes teóricas sobre terapias alternativas tomou como contexto a especificidade comunicativa das relaçōes consideradas terapêuticas em geral (acta).

2. O critério de explicação está baseado em um pressuposto "cético" do não reconhecimento de poderes místicos ou "eu considero, assim, que seja alternativa, porque eu posso falar do que eu quiser, sabe, ele nõo conduz a entrevista em nenhum momento" 
mágicos, mas sim do reconhecimento do uso da retórica mitica ou mágica enquanto fortalecimento de poder pessoal de influência (acta).

3. As descriçōes oferecidas pelos pacientes trazem as mesmas características narrativas e metafóricas de descriçōes oferecidas por pacientes de terapias convencionais (data) (vide Gomes el al, 1988; 1993), o que permite identificá-las como constituindo-se em uma mesma forma estrutural (capta). Assim, as características descriminatórias destes tratamentos, conforme descrição de terapeutas e pacientes não foram consideradas como especificadoras (acta).

4. Os terapeutas mostraram, em suas entrevistas, como articulam teoria e técnica (data), deixando transparecer a sincronia entre ação técnica e açāo comunicativa (capta) em diacronias como, por exemplo, a ênfase numa associação forçada entre uma essência floral e a crença no seu efeito (data), o que sugere a realização de estudos focais sobre essas associações (capta).

5. Os terapeutas não indicaram em suas respostas elementos mágicos ou místicos mas mostraram-se conscientes de aspectos convencionais de estruturas terapêuticas (diferenciação de expressão de sintoma vs. percepção de processo psicológico - data). No entanto, tal comportamento verbal pode estar associado à percepção da vinculação dos pesquisadores ao saber convencional, ou a procura de uma linguagem conhecida $e$ respeitada pelos pesquisadores ou, ainda, ao modo de acesso a este grupo seleto de terapeutas. Eles foram indicados por estudantes de psicologia ao serem por estes classificados como "alternativos sérios" o que, por oposição, conota a existência de alternativos não-sérios, que não foram mas deveriam ter sido entrevistados (capta).

6. As articulaçōes entre teoria, psicopatologia, técnica e processo, nas diferentes modalidades de tratamento (data), foram tipificadas como especificadoras (os tratamentos apresentam características próprias - capta), o que sugere a realização de estudos específicos para cada tratamento (acta). Tais estudos devem considerar também a literatura de referência destas teorias para restabelecer os alegados e subjacentes pressupostos ontológicos e epistemológicos (construção versus desconstrução).

7. Ressalte-se nas respostas (data) a supremacia explicativa dos psicólogos em comparação com os terapeutas que não são psicólogos (capta). Todavia, não podemos sustentar que maior habilidade de explicaçāo teórica assegure maior habilidade de performance técnica, principalmente se por ação técnica se entenda um modo peculiar de se colocar em uma comunicação interpessoal dominante (acta).

8. Qual a validade destas interpretaçổes? Qual a fidedignidade dos recortes das entrevistas efetuados pelos pesquisadores? Qual a confiabilidade das descriçōes oferecidas pelos participantes da pesquisa? A fala da experiência terapêutica remete necessariamente à consciência do benefício terapêutico? Mas, afinal, o que é benefício terapêutico? Seria o desaparecimento do sintoma? Ou, ao contrário, seria a exacerbação do sintoma? Ou, ainda, a convivência amistosa com o sintoma? Ou, quem sabe, a aceitação do sintoma como a mais legitima expressão de si? Ou, todavia, a discriminaçāo do sintoma como um hábito arraigado? Enfim, o que na experiência de conjunçōes entre expressão (como respondo ao outro e a mim mesmo) e percepçōes (como penso as minhas respostas ao outro e a mim mesmo) deve ser considerado sintoma? Estas perguntas abrem um imenso leque para interpretaçōes a partir do grande número das teorias terapêuticas convencionais. Na verdade, a comunalidade das respostas apresentadas com estudos similares sobre eficiência terapêutica levantam questões metodológicas importantes.

9. Descriçōes qualitativas são apenas indicadores de tipicalidades. Apontam para ocorrências e recorrências no mundo sem nenhuma força universalizadora. Se estudos similares com terapias convencionais trazem alguma verdade, alguma verdade existe nas conclusōes apresentadas. Caso contrário, ou o método é inadequado ou sabemos muito pouco do processo e eficiência terapêutica. De qualquer forma, as conclusōes deste estudo sugerem, de acordo com a literatura, que o diferencial terapêutico não está na teoria (ideologia) mas na pessoa que está em um lugar dito terapêutico (retórica), mesmo em situaçōes que surpreendem o status quo. Nestes termos, tomando-se as teorias estudadas como integrantes de um mesmo contexto repete-se a premissa de que diferentes concepções teóricas dos terapeutas não tipicalizam percepções de experiências terapêuticas para os pacientes.

10. Reconheca-se, todavia, que estes terapeutas mostraram-se preocupados com a regulamentação de suas práticas, com a legitimidade de sua formação alternativa, com os limites de seu conhecimento técnico/teórico e com a pesquisa da eficiência de suas técnicas. 


\section{Discussão}

Implicações lógico-metodológicas dos resultados.

A Revista "American Psychologist" (1996) trouxe na capa de um número dedicado à avaliação de resultados de psicoterapia o seguinte comentário de Hans H. Strupp, um dos mais importantes pesquisadores em eficiência psicoterapêutica: o problema de avaliação de resultados da psicoterapia continua incomodando a área como fazia há um século atrás, quando a psicoterapia moderna estava apenas começando. Apesar de centenas de estudos e de demonstraçōes freqüentemente repetidas de que pessoas que passam por tratamentos psicoterapêuticos se beneficiam de uma forma ou de outra, ainda persiste um ceticismo generalizado, e cada estudo adicional é tratado como se fosse o primeiro.

Na verdade, o número especial do "American Psychologist" dedicado à avaliaçâo dos resultados das psicoterapias traz as repercussōes de um artigo polêmico publicado um ano antes na mesma revista. Neste artigo, Seligman (1995) apresenta e discute um conjunto de dados sobre eficiência psicoterapêutica obtidos através de uma pesquisa de opinlão do "Consumer Reports" (1995, November). Os principais resultados são os seguintes: pacientes beneficiam-se substancialmente dos tratamentos psicológicos; tratamentos de longa duraçāo (entre seis a dezoito meses) apresentaram melhores resultados que tratamentos de curta duração; resultados de psicoterapia não diferem em eficiência de resultados de psicoterapia combinada com medicação; nenhuma modalidade terapêutica mostrou-se melhor do que outra em qualquer tipo de desordem; psicólogos, psiquiatras e assistentes sociais não se diferenciam em sua eficiência como terapeutas. No entanto, o aspecto de particular interesse neste artigo é de que a pesquisa de opiniāo do "Consumer Reports" mostrou-se um complemento importante para os estudos tradicionals e bem controlados sobre eficácia terapêutica. Por pesquisa de eficácia (efficacy) entende-se aqueles estudos que utilizam grupos de controle, número fixo de sessōes, técnicas determinadas por manuais e que selecionam sujeitos com problemas psicológicos muito bem definidos e minuciosamente diagnosticados. Por pesquisa de eficiência (effectiveness) entende-se aqueles estudos retrospectivos que abordam as pessoas no mundo real, onde não existem controles previamente determinados.
As conclusōes de Seligman são importantes para um exame crítico da metodologia em uso nesta pesquisa. $\mathrm{Na}$ avaliaçāo de Seligman a metodologia do estudo da "Consumer Reports" vai ao encontro da prática que ocorre de fato no mundo real das psicoterapias. Nesse mundo, não há número de sessōes previamente determinado, o tratamento é autocorretivo, pacientes em geral tendem a ser ativos (iniciativa própria de buscar o tratamento) e não passivos (encaminhado por algum profissional ou serviço), os problemas são múltiplos e há uma preocupação clínica com a melhoria geral do paciente.

Os dois aspectos mais questionáveis da metodologia do presente estudo são: 1) a utilizaçāo de auto-relatos e 2) referir-se a experiências retrospectivas. Seligman argumenta então que pode haver incorreções em auto-relatos sobre o que levou a pessoa ao tratamento, o tipo de terapia que ela fez ou está fazendo, dificuldades em avaliar suas melhoras em problemas específicos, na produtividade no trabalho e nas relaçōes interpessoais. Contudo, estas incorreçōes são aletórias e não sistemátcas, e estāo sempre presentes nas relaçōes entre terapeuta e paciente. Complementa Seligman que a correlação entre diagnósticos e auto-relatos é alta.

Os principais comentários referentes às posições de Seligman (1995) que aparecem no número especial do "American Psychologist" (1996) apontam, principalmente, para defesas de preferências metodológicas na avaliação de resultados de psicoterapias. Há defesas ardorosas de estudos de eficácia (Hollon, 1996, e Jacobson \& Christensen, 1996). Por outro lado, há um consenso entre os pesquisadores de que dados obtidos por auto-relatos, desde que complementados por outros tipos de estudo, como, por exemplo, estudos de caso único (Goldfried \& Wolfe, 1996) ou um modelo tríplice constituindo-se em: 1) observação para verificação de comportamento adaptativo, 2) auto-relato para comunicação de senso de bem estar e 3) exame de estrutura de personalidade (Strupp, 1996). Ressalte-se contudo que Jacobson e Christensen (1996) reconheceram que estudos de caso único e métodos de pesquisa qualitativa "são especialmente relevantes para os terapeutas e que nesta área os terapeutas podem desempenhar um papel importante no delineamento e execução de seus estudos" (p. 1038). Estudos defendem o uso de métodos diferentes na avaliação de eficiência terapêutica, considerando que se deve estender os delineamentos das pesquisas de resultados de psicoterapias a fim de que se 
alcance com eles tópicos dos estudos de eficiêncla (Walsh, 1995). Há, ainda, a proposta de uma abordagem hermenêutica da questão dos valores em jogo na avaliação de resultados de psicoterapias (Clarke, 1995).

Por meio do uso de métodos qualitativos de pesquisa em psicoterapia (Gomes, Reck, Bianchi \& Ganzo, 1993) adquire-se uma perspectiva que é concomitantemente mais abrangente e mais rigorosa do que a tradição de ciência natural comum aos estudos da eficácia psicoterapêutica. Trabalha-se com auto-relatos e experiências retrospectivas, mas o modo de abordagem é clínico. As entrevistas, ao contrário dos questionários, não demarcam contextos, mas oferecem pistas para que contextos sejam construídos. $O$ entrevistador acompanha a formulação das respostas esclarecendo com o entrevistado os sentidos da mensagem. Assim, a pesquisa qualitativa, da mesma forma que a boa psicoterapia, é também autocorretiva. A atitude fenomenológica da suspensão de pressupostos e a evidência semiótica das descriçōes levam-nos a análises estruturais que detectam possiveis incorreçōes. Transformaçōes de "capta" (interpretações qualitativas) em dados (interpretações quantitativas) e o reverso asseguram aos nossas achados (conclusōes empíricas) e tomados (conclusōes eidéticas) a validaçāo nos termos definidos por Guba (1981): coerência geral da pesquisa resultará em credibilidade (validade interna); descrições paralelas resultarão em transferibilidade (validade externa), uso de instrumentos simultâneos resultará em estabilidade (fidedignidade); e apresentação de interpretaçōes baseada em diferentes perspectivas produzirá análises confirmatórias.

Desta forma, as interpretaçōes apresentadas devem ser vistas com cautela mas apontam para uma avenida de possibilidades no estudo destes tratamentos. Novos estudos devem ser realizados comparando-se casos clínicos de uma única abordagem e também procurando esclarecer a contribuição que profissionais com formação em psicologia estão levando para estas práticas.

\section{Implicaçōes epistemológicas dos resultados}

Na revisão de literatura no início deste texto foram apresentadas duas interpretaçōes radicais sobre os tratamentos alternativos. Lembre-se que Marques (1994) reconheceu nestes tratamentos indícios de novos paradigmas psicológicos decorrentes da pósmodernidade. Ao contrário, Tourinho e
Carvalho (1995) identificaram nos tratamentos alternativos uma incompatibilidade lógica entre a conjunção de caso e resultado com o enunciado de regras explicativas. Para os autores as explicaçōes apresentadas como justificativas da relação entre caso (sintoma e intervenção) e resultado terapêutico contrariam os pressupostos aceitos pela tradição de ciência natural ou de ciência humana em psicologia.

Os resultados do presente estudo, embora atrelados a uma lógica de ciência humana rigorosa, mas sem negar a importância do uso da lógica da ciência natural no estudo de fenômenos psicológicos, apontam para a necessidade da investigaçāo empírica das técnicas alternativas. Primeiro, reconhece que influências tidas como terapêuticas estão presentes em uma grande variedade de relaçōes interpessoais, artísticas, religiosas, culturais e reflexivas. Segundo, entende que é dever dos pesquisadores em psicologia investigarem e dominarem as propriedades psicológicas destas influências. As técnicas usadas nestes tratamentos, seja através de retórica, reagentes químicos ou exercícios físicos devem ser cuidadosamente investigado. Deve-se focalizar o fenômeno em si e não as possíveis explicações destes fenômenos. Terceiro, este estudo não vê nestes tratamentos nenhum prenúncio de pós-modernidade, pois o que parece ocorrer é a substituição de dogmas convencionais por dogmas não convencionais. Não há uma preocupação em manter qualquer pressuposto sempre sokre suspeita (vide, por exemplo, Gadamer, 1989). Quarto, espera-se que estas pesquisas ampliem a compreensāo destes fenômenos e subsidiem programas preventivos e remediadores de intervenções psicológicas, tendo como contexto o universo de crenças culturais. Por último, interpreta-se que a procura dos psicólogos por formaçāo em terapias alternativas pode estar relacionada com dificuldades na clarificaçāo de pressupostos pessoais e das relaçōes destes com pressupostos históricos e científicos da psicologia. 
Augras, M. (1983). O duplo e a metamorfose: A identidade mítica em comunidades Nagô. Petrópolis: Vozes.

Bergin, A. E., \& Jensen, J. P. (1990). Religiosoty of psychtherapists: A national survey. Psychotherapy. Theory Res. Pract. Train. 27, 3-7.

Bogart, G. (1991). The use of meditation in psychotherapy: A review of literature. American Journal of Psychotherapy, 45, 383-412.

Clarke, G. N. (1995). Improving the transition from basic efficacy research to effectiveness studies: methodological issues and procedures. Journal of Consulting and Clinical Psychology, 63, 718-725.

Csordas, T. J. (1990). The psychotherapy analogy and charismatic healing. Psychother. Theory Res. Pract. Train. 27, 79-90.

Dorin, E.(1978). Dicionário de Psicologia. São Paulo: Ediçōes Melhoramentos.

Fadiman, J., \& Frager, R. (1979). Teorias da personalidade. São Paulo: Harper \& Row do Brasil.

Goldfried, M. R., \& Wolfe, B. E. (1996). Psychotherapy practice and research: repairing a strained alliance. American Psychologist, 51, 1007-1016.

Gadamer, H. G. (1989). Truth and method (2nd rev. ed.). (J. Weinsheimer \& D. G. Marshall, trans.). New York: Corssroads.

Gomes, W. (1997). A entrevista fenomenológica e o estudo da experiência consciente. Psicologia USP, 8(2), 305-336.

Gomes, W. Reck, A., \& Ganzo, C. (1988). A experiência retrospectiva de estar em psicoterapia: um estudo empírico fenomenológico. Psicologia: Teoria e Pesquisa, 4, 187-206.

Gomes, W. Reck, A. Bianchi, A., \& Ganzo, C. (1993). $O$ uso de indicadores quantitativos e descritores qualitativos na pesquisa em psicoterapia. Psicologia: Teoria e Pesquisa, 9, 415-433.

Guba, E. G. (1981). Criteria for assessing the trustworthiness of naturalistic inquires. ECTG, 29(2), 75-91.

Havenaar, J. M. (1990). Psychotherapy: healing by culture. Psychother. Psychosom. 53, 8-13.

Hollon, S. D. (1996). The efficacy and effectiveness of psychotherapy relative to medications. American Psychologist, 51, 1025-1030.

Ikemi, Y. (1990). Psychosomatic medicine as a core of holistic medicine: present state and future of PSM. Psychosom. Med., 30, 251-260. Jacobson, N. S. \& Christensen, A. (1996). Studying the effectiveness of psychotherapy: How well can clinical crials do the job? American Psychologist, 51, 10311039.
Jung, C. G. (1964). O homem e seus símbolos. Rio de Janeiro: Nova Fronteira.

Referências bibliográficas

Lanigan, R.L. (1988). Phenomenology of communication: Merleau-Ponty's thematics in communicology and semiology. Pittsburgh: Duquesne University Press.

Littlewood, R. (1990). How universal is something we can call 'Therapy'? Some implications of non-western healing systems for intercultural work. Holistic Medicine. 5, 49-65.

Marques, L. F. (1994). Práticas alternativas em psicoterapia num cenário de mudança de paradigma. Dissertação de mestrado não publicada, PUCRS, Porto Alegre, RS.

Omer, H., \& Strenger, C. (1992). Pluralistic criteria for psychotherapy: an alternative to sectarianism, anarchy, and utopian integration. American Journal of Psychotherapy, 46, 111-130.

Patton, M.G. (1990). Qualitative evaluation methods. Beverly Hills, CA: Sage.

Pfeiffer, W. (1991). What does make a conversation therapeutic?. Psychother. Psychosom. Med. Psychol. 41, 93-101.

Rhee, D. (1990). The Tao, Psychoanalysis and existential thought. Psychother. Psychosom. 53, 21-27.

Sarai, K. (1992). Oriental medicine as therapy for resistant depression: use of some herbal drugs in the far east. Prog. Neuro. Psychopharmacol. Biol. Psychiatry. 16, 171-180.

Seligman, M. E. P. (1995). The effectiveness of psychotherapy: the Consumer Reports study. American Psychologist, v. 50, 965-974.

Seligman, M. E. P. (1996). Science as an ally of practice. American Psychologist,. 51, 1072-1079.

Straker, G. (1994). Integrating african and western healing practices in South Africa. American Journal of Psychotherapy, 48, 455-467.

Strupp, H. H. (1996). The Tripartite Model and the Consumer Reports study. American Psychologist, 51, 1017-1024.

Tabone, M. (1992). A Psicologia Transpessoa: Introdução à nova visão da consciência em psicologia e educação. São Paulo: Cultrix.

Tourinho, E. Z., \& Carvalho, M. B. N. (1995). As fronteiras entre a Psicologia e as práticas alternativas: algumas consideraçōes. Psicologia no Brasil: Direçōes epistemológicas. (pp. 81-110). Brasília: Conselho Federal de Psicologia.

Vontress, C. E. (1991). Traditional healing in Africa: implications for cross-cultural counseling. Journal of Counseling and Development, 70, 242-249.

Walsh, R. A. (1995). The study of values in Psychotherapy: a critique and call for an alternative method. Psychotherapy Research, 5(4), 313-326. 


\title{
Anexo 1 PRotocolos tópicos das ENTREVISTAS
}

\author{
PROTOCOLO DE ENTREVISTA COM TERAPEUTA
}

Abertura: Estou desenvolvendo uma pesquisa com o objetivo de levantar dados sobre a experiência de praticar terapia alternativa e a de estar em terapia alternativa. Eu tenho um roteiro de entrevista, mas o importante é o teu depoimento. A entrevista será gravada, e o que disseres permanecerá confidencial. Tens alguma dúvida?

1. Como foi isso, de seguir um caminho alternativo em terapia?

2. E como foi a tua formação (onde, quanto tempo durou, formal/informal)?

3. Tu recebeste outro tipo de formação (como, onde, formal/informal)?

4. Tu ainda participas de alguma formação (cursos, workshops, intercâmbio com colegas...)?

5. Se não, gostarias de fazê-lo?

6. O que peculiariza a tua prática?

7. Quai são os recursos técnicos que tu usas no tratamento?

8. Em que sentido isso facilita o processo?

9. O que caracteriza o processo, como evolui o tratamento, de sessão a sessão?

10. Quais problemas sāo mais freqüentemente trazidos pelos teus pacientes?

11. Quanto tempo dura, em média, uma sessão?

12. Quem fala mais na sessão?

13. Como tu consegues teus pacientes?

14. Quantos pacientes tu vês por semana?

15. Como tu decides quando terminar o tratamento?

16. Como tu acreditas que se dá a cura por esse método?

\section{PROTOCOLO DE ENTREVISTA COM PACIENTE}

Abertura: Estou desenvolvendo uma pesquisa com o objetivo de levantar dados sobre a experiência de praticar terapia alternativa e a de estar em terapia alternativa. Eu tanho um roteiro de entrevista, mas o importante é o teu depoimento. A entrevista será gravada, e o que disseres permanecerá confidencial. Tens alguma dúvida?

1. Como é isso de estar em psicoterapia?

2. O que acontece quando tu estás com teu/tua terapeuta, por exemplo, o que passa nos teus pensamentos, sentimentos...?

3. Quando termina a sessão, como tu em geral te sentes, o que passa nos teus pensamentos, sentimentos, corpo...?

4. O que acontece na sessäo quando ao final tu te sentes bem, ou ao contrário, quando tu te sentes mal?

5. Em geral, qual das duas situaçōes é mais freqüente?

6. O que se passa contigo entre uma sessão e outra?

7. Tu pensas muito no que foi dito ou ouvido?

8. As coisas ditas e ouvidas ficam, assim, indo e vindo na tua cabeça?

9. Tu consegues notar alguma relaçāo entre essas lembranças da terapia com os muitos pensamentos decorrentes e alguma modificação na tua meneira de pensar, agir, sentir...?

10. O que acontece quando se aproxima a terapia, assim, quando tu estás indo falar com o terapeuta, ou quando tu estás na sala de espera?

11. Como tu te descreves, digamos, antes de começar a terapia?

12. Como foi que tu decidiste fazer terapia?

13. Como tu te descreves hoje?

14. (Se for o caso) Tu falaste de mudança; dá para dizer como acontecem, quando acontecem e em que acontecem?

15. Como tu descreves o teu terapeuta, como ele/ela é contigo?

16. Como é o teu relacionamento com ele/ela?

17. Como começa a sessão, quem fala primeiro?

18. Como termina a sessäo?

19. Qual relação tu vês entre as coisas de que o teu terapeuta fala e as mudanças que ocorrem contigo?

20. Como tu anteciparias ofim da terapia?

21. Como tu acreditas que serás depois da terapia; vai ser possível viver sem ela? 